\title{
Child Developmental Screening in Southern Iran
}

\author{
Shirin Soltani, ${ }^{1}$ Soghra Kamali, ${ }^{1}$ Nasibeh Roozbeh, ${ }^{1,}$, and Leili Darvish ${ }^{1}$ \\ ${ }^{1}$ Mother and Child Welfare Research Center, Hormozgan University of Medical Sciences, Bandar Abbas, Iran \\ "Corresponding author: Nasibeh Roozbeh, Mother and Child Welfare Research Center, Hormozgan University of Medical Sciences, Bandar Abbas, Iran. Tel: +98-3334044, E-mail: \\ nasibe62@yahoo.com
}

Received 2016 July 18; Revised 2016 September 13; Accepted 2016 September 30.

\section{Dear Editor,}

More than 200 million children in low- and middle-income countries suffer from developmental delays and / or debilities worldwide (1). Some risk factors associated with practical damage and mental developmental delay in infants and children in developing countries are as follows: Micronutrient deficiency, malnutrition, poor health and hygiene, and scarce care. Early detection of developmental problems is of importance to the wellbeing of young children and their parents. Therefore, it is essential to decrease the negative outcomes (2). The Ages and stages questionnaire (ASQ), which has largely been used in contemporary studies, is a developmental screening questionnaire designed to be completed by parents or primary caregivers of children. This questionnaire can detect those children who should be further evaluated to decide whether they are qualified for early intervention, or early childhood specific training. Sensitivity, specificity and reliability of this questionnaire (ASQ) have been reported to be $75.8 \%, 87.5 \%$, and $94 \%$, respectively (3). The ASQ is used for children aged 4 - 60 months, covering five various domains of communication, fine motor, problem solving, gross motor, and personal-social skills (1). In 2015, in a cross-sectional study in Hormozgan province (located in the extreme point of southern Iran) 23,494 twelve-month-old children were screened for development delay, using the ASQ. Among the participants, the ASQ was abnormal in 88 children. Moreover, $25 \%$ had a delay in communication domain, $29 \%$ in fine motor, $31 \%$ in problem solving, $35 \%$ in gross motor, and $26 \%$ in personal-social skills. The results revealed that 'delay in gross motor' and 'problem solving' were higher among all the domains. Gross motor development includes control and movement of large muscle groups such as the head, torso, arms, and legs. Gross motor skills are abilities that have been developed during early childhood, and they develop from top to bottom (4). The 'problem solving domain' includes child's knowledge and the ability to play with toys. However, these results should not be interpreted in isolation, and decisions should be made based on other factors and the overall function of children. A systematic review summarized the results of studies and provided the best evidence for judging (5). Therefore these studies can help to identify the effective factors on delay in gross motor and problem solving domains.

\section{References}

1. Van der Linde J, Swanepoel DW, Glascoe FP, Louw EM, Vinck B. Developmental screening in South Africa: comparing the national developmental checklist to a standardized tool. African Health Sciences. 2015;15(1):188. doi: 10.4314/ahs.v15i1.25.

2. Yaghini O, Kelishadi R, Keikha M, Niknam N, Sadeghi S, Najafpour E, et al. Prevalence of Developmental Delay in Apparently Normal Preschool Children in Isfahan,Central Iran. Iran J Child Neurol. 2015;9(3):17-23. [PubMed: 26401149].

3. Vameghi R, Sajedi F, Kraskian Mojembari A, Habiollahi A, Lornezhad HR, Delavar B. Cross-Cultural Adaptation, Validation and Standardization of Ages and Stages Questionnaire (ASQ) in Iranian Children. Iran J Public Health. 2013;42(5):522-8. [PubMed: 23802111].

4. Piek JP, Dawson L, Smith LM, Gasson N. The role of early fine and gross motor development on later motor and cognitive ability. Hum Mov Sci. 2008;27(5):668-81. doi: 10.1016/j.humov.2007.11.002. [PubMed: 18242747].

5. Abdi F, Roozbeh N. The effects of Humulus Lupulus L. (Hops) on Menopausal Vasomotor Symptoms: A Systematic Review and Meta-analysis. IJOGI. 2016;19(26):9-7. doi: 10.22038/ijogi.2016.7797. 